\title{
Glucose transport by the phosphoenolpyruvate:mannose phosphotransferase system in Lactobacillus casei ATCC 393 and its role in carbon catabolite repression
}

\author{
Ana Veyrat, Vicente Monedero and Gaspar Pérez-Martínez
}

Author for correspondence: Gaspar Pérez-Martínez. Tel: +346 3690800. Fax: +3463930001.

Instituto de Agroquímica y Tecnología de Alimentos (CSIC), Jaime Roig 11 , E-46010 Valencia, Spain

\begin{abstract}
A 2-deoxy-D-glucose-resistant mutant of a pLZ15-cured derivative of Lactobacillus casei ATCC 393 was isolated on agar medium containing $10 \mathrm{mM}$ 2-deoxy-D-glucose and 5 g lactose $\mathrm{I}^{-1}$. The mutant was impaired in the main

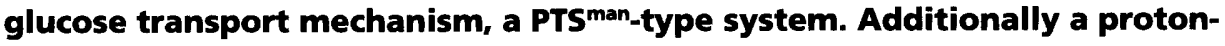
motive-force-dependent glucose permease was detected. The growth response and the sugar consumption rates of the wild-type and the PTS ${ }^{\text {man }}$-deficient mutant suggested that the mutated element of the complex IIABCman was, in the wild-type, responsible for a strong repression by glucose and mannose of the lactose and ribose assimilation genes, while assimilation of galactose was only weakly repressed. It is postulated that they are regulated by a different mechanism of catabolite repression.
\end{abstract}

Keywords: Lactobacillus casei, glucose transport, phosphoenolpyruvate-dependent phosphotransferase system, catabolite repression

\section{INTRODUCTION}

In a number of bacterial species, the most efficient mechanism of sugar entry into the cell is via the phosphoenolpyruvate (PEP)-dependent phosphotransferase system (PTS) (Romano et al., 1979). The PTS involves three to four enzymes performing a phosphate group translocation from PEP to the sugar residue, which is transported to the cytosol. The PTS system has long been considered the main signal transduction system in prokaryotes, triggering a number of regulatory pathways, from chemotaxis (Lengeler et al., 1981) to the control of biochemical pathways and the repression of a number of genes, which in most cases are related to the use of sugar polymers or alternative carbon sources (see Meadow et al., 1990; Saier \& Reizer, 1992; Postma et al., 1993).

In Eschericbia coli, glucose reaches the cytoplasm mainly

\footnotetext{
Abbreviations: PEP, phosphoenolpyruvate: PTS, PEP-dependent phos-

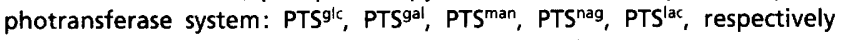
identifying sugar-specific PTS for glucose, galactose, mannose, $\mathrm{N}$ acetylglucosamine and lactose; CCCP, carbonyl cyanide $m$-chlorophenylhydrazone; IAA, iodoacetic acid; PMB, phosphate buffer $(\mathrm{pH} 7 \cdot 4)$ containing $1 \mathrm{mM} \mathrm{MgCl}$; 2DG, 2-deoxy-D-glucose; $\alpha$-MG, methyl $\alpha$-Dglucopyranoside; PMF, proton-motive force.
}

via a glucose-specific $\mathrm{PTS}^{\mathrm{glc}}$ and via the mannose-specific PTS $^{\text {man }}$ (Bitoun et al., 1983; Erni \& Zanolari, 1986; Erni et al., 1987). However, it can also be transported by other PTS systems, such as the $N$-acetylglucosamine-specific PTS (PTS $\left.{ }^{\text {nag }}\right)$. Both PTS ${ }^{\text {glc }}$ and PTS ${ }^{\text {man }}$ have greater affinity for glucose than for mannose and they can also transport other hexoses and sugar analogues, which can be used to differentiate the two systems: for example, 2-deoxy-D-glucose (2DG) and methyl $\alpha$-D-glucoside $(\alpha-M G)$ have specific affinity for the complex II ${ }^{\text {man }}$ and II $^{\text {glc }}$ respectively.

Among Gram-positive bacteria, streptococci have been reported to possess both the PTS ${ }^{\text {glc }}$ and PTS $^{\text {man }}$ systems, in addition to a proton-motive-force (PMF)-driven permease, while Bacillus spp. have been found to use the PMF-permease and a PTS ${ }^{\text {gle }}$ exclusively (Meadow $e t$ al., 1990; Gonzy-Tréboul et al., 1991; Tanguey et al., 1993). In the lactic acid bacteria Lactococcus lactis and Pediococcus balophilus, glucose has been shown to be transported via PTS $^{\text {man }}$ and a specific PMF-dependent glucose permease, and the existence of a PTS ${ }^{\operatorname{man}}$ in Lactobacillus case $i$ has been suggested (Chassy \& Thompson, 1983a, b; Thompson \& Chassy, 1985; A be \& Uchida, 1989). These findings suggest that lactic acid bacteria lack a PTS ${ }^{\text {glc }}$ homologous to that of E. coli. However, the regulatory role of PTS ${ }^{\text {man }}$ 
in these organisms is yet to be fully ascertained. Inducer exclusion assays performed in Lc. lactis (Thompson \& Chassy, 1985) and P. balophilus (Abe \& Uchida, 1989) suggested that glucose was involved in the inducer exclusion event, and possibly in the repression of the transcription of the transport or metabolic genes necessary for the assimilation of lactose, galactose and xylose.

The objective of the present work was to study the elements involved in the transport of glucose and catabolite repression, in the wild-type and a 2DG-resistant mutant of Lb. casei.

\section{METHODS}

Bacterial strains and culture conditions. Lactobacillus casei ATCC 393, cured of plasmid pLZ15, was kindly provided by Dr B. Chassy (University of Urbana-Champaign, IL, USA). Strains were routinely cultured under static conditions at $37^{\circ} \mathrm{C}$. The fermentation pattern of the strains was determined on a range of 18 different sugars in microtitre plates (Jayne-Williams, 1976).

For the experiments on sugar consumption and diauxic growth, strains were grown on basal medium, containing per litre: Bactopeptone (Difco), $10 \mathrm{~g}$; meat extract (ADSA-MICRO SA), $8 \mathrm{~g}$; yeast extract (Difco), $4 \mathrm{~g} ; \mathrm{K}_{2} \mathrm{HPO}_{4}, 2 \mathrm{~g}$; sodium acetate, $5 \mathrm{~g}$; ammonium citrate, $5 \mathrm{~g} ; \mathrm{MgSO}_{4} .7 \mathrm{H}_{2} \mathrm{O}, 0.2 \mathrm{~g}$; $\mathrm{MnSO}_{4} \cdot 4 \mathrm{H}_{2} \mathrm{O}, 0 \cdot 05 \mathrm{~g}$; and Tween $80,1 \mathrm{ml}$. The medium was supplemented with $1.5 \mathrm{~g} \mathrm{l}^{-1}$ glucose or mannose and $5 \mathrm{~g} \mathrm{l}^{-1}$ of the second sugar tested: lactose, galactose or ribose. The components of MRS medium were those of the basal medium with the addition of $20 \mathrm{~g}$ glucose $\mathrm{l}^{-1}$ (Oxoid). Mutants resistant to 2DG were isolated on Fermentation MRS agar plates (ADSAMICRO), which contained all the components of MRS except meat extract, $\mathrm{K}_{2} \mathrm{HPO}_{4}$ and glucose.

PEP-dependent PTS activity and glucose phosphorylation assay in permeabilized cells. The PTS activity, estimated as the consumption of PEP in the presence of glucose, mannose and $\alpha-M G$, was determined according to Chassy \& Thompson (1983a).

The procedure used to measure the amount of glucose 6phosphate formed was that of Abe \& Uchida (1989) with some modifications. $L b$. case $i$ was grown to early stationary phase $(16 \mathrm{~h})$ in $50 \mathrm{ml}$ basal medium with $5 \mathrm{~g}$ glucose $\mathrm{l}^{-1}$, and the cells collected by centrifugation. Cells were washed twice with $0.01 \mathrm{M}$ potassium phosphate buffer $(\mathrm{pH} 7.4)$ containing $1 \mathrm{mM}$ $\mathrm{MgCl}_{2}$ (PMB), and finally resuspended to a concentration approximately equivalent to $20 \mathrm{mg}$ dry weight $\mathrm{ml}^{-1}$. Cellular reserves were depleted by preincubation of the cell suspension for $10 \mathrm{~min}$ at $37^{\circ} \mathrm{C}$. Then iodoacetic acid (IAA) was added (10 $\mathrm{mM}$ final concentration) and incubation continued for a further $20 \mathrm{~min}$ at $37^{\circ} \mathrm{C}$. Cells were permeabilized by adding $30 \mu \mathrm{l}$ toluene/acetone $(1: 9, \mathrm{v} / \mathrm{v}) \mathrm{ml}^{-1}$ followed by vortexshaking for $5 \mathrm{~min}$. Suspensions were kept on ice until use. The phosphorylation assays were performed in $1 \mathrm{ml}$ of a mixture containing $50 \mathrm{mM}$ triethanolamine $(\mathrm{pH} \mathrm{7.4}), 10 \mathrm{mM} \mathrm{MgCl}$, $5 \mathrm{mM}$ PEP or ATP (as indicated), $1.5 \mathrm{mM}$ NADP, 3 units glucose-6-phosphate dehydrogenase, $200 \mu \mathrm{g}$ dry weight of cells and glucose at varying concentrations, from 0 to $10 \mathrm{mM}$. The phosphorylation reaction was followed by measuring the change in $A_{340}$ at room temperature. Activity is given as nmol phosphorylated glucose $\min ^{-1}$ ( $\mathrm{mg}$ dry weight $)^{-1}$.

Glucose transport assays. $\mathrm{D}-\left[{ }^{14} \mathrm{C}\right]$ Glucose uptake by whole cells of $L b$. case $i$ was estimated according to Chassy \&
Thompson (1983a, b). Cells grown in $250 \mathrm{ml}$ basal medium with $5 \mathrm{~g}$ glucose $1^{-1}$ to $\mathrm{OD}_{550} 0 \cdot 4-0 \cdot 6$ were collected by centrifugation, washed twice with PMB and finally resuspended in $5 \mathrm{ml}$ PMB. Keeping the cells on ice at this stage is essential to maintain PEP potential. The amount of cells used for each assay corresponded to $100 \mu \mathrm{g}$ dry weight $\mathrm{ml}^{-1}$. Four flasks were used for each strain, containing $15 \mathrm{ml}$ of the cell suspension in PMB with $10,25,75$ and $125 \mu \mathrm{M}$ glucose at $37^{\circ} \mathrm{C}$. To another set of four flasks for each strain, CCCP was added to a final concentration of $0.1 \mathrm{mM}$. At different time intervals after the addition of $\mathrm{D}-\left[\mathrm{U}-{ }^{14} \mathrm{C}\right]$ glucose $\left(0.3 \mathrm{mCi} \mathrm{mmol}^{-1} 11 \cdot 1 \mathrm{MBq}\right.$ $\mathrm{mmol}^{-1}$; Amersham), $1 \mathrm{ml}$ aliquots were withdrawn and quickly cooled by mixing with $10 \mathrm{ml}$ ice-cold PMB. The samples were then filtered through $0.45 \mu \mathrm{m}$ membrane filters (HAWP 02500, Millipore) and further washed with $10 \mathrm{ml}$ ice-cold PMB. Filters were dried and dissolved in scintillation cocktail (Hisafe3, LKB). Radioactivity was quantified with a scintillation counter (Pharmacia-LKB Biotechnology).

Growth pattern determination. The preferential use of different sugars by $L b$. case $i$ was determined in cells grown on basal medium containing $5 \mathrm{~g} \mathrm{l}^{-1}$ of glucose, lactose, galactose or mannose, as indicated. When the stationary phase was reached, cells were subcultured into $50 \mathrm{ml}$ basal medium containing $1.5 \mathrm{~g} \mathrm{l}^{-1}$ glucose or mannose (preferential sugars) and $5 \mathrm{~g} \mathrm{l}^{-1}$ of lactose, galactose or ribose, according to the experimental design. The initial $\mathrm{OD}_{550}$ was $0 \cdot 1$. Periodically, samples were taken to measure growth (as $\mathrm{OD}_{550}$ ) and sugar content.

Analysis of sugars. The concentrations of glucose, galactose, lactose and mannose in culture supernatants were determined spectrophotometrically as described by Bergmeyer (1984). All enzymes and chemicals were purchased from Boehringer Mannheim.

\section{RESULTS AND DISCUSSION}

\section{Isolation of a 2DG-resistant mutant of $L b$ casei ATCC 393}

A spontaneous mutant resistant to 2DG was isolated on Fermentation MRS agar plates containing $5 \mathrm{~g} \mathrm{l}^{-1}$ lactose as carbon source and $10 \mathrm{mM} 2 \mathrm{DG}$. This strain, named BL23D, displayed a sugar fermentation pattern identical to the wild-type, with the difference that its specific growth rate on basal medium with glucose $\left(0.071-0.077 \mathrm{~h}^{-1}\right)$ was slower than that of the wild-type $\left(0.088-0.091 \mathrm{~h}^{-1}\right)$. As shown below, this mutant proved to be deficient in the PTS ${ }^{\text {man }}$ system.

\section{Growth pattern on glucose and mannose}

The growth response of mutant BL23D and the wild-type were compared on basal medium supplemented with a mixture of $1.5 \mathrm{~g}$ glucose $\mathrm{l}^{-1}$ and $5 \mathrm{~g}$ mannose $\mathrm{l}^{-1}$. In the wild-type, the consumption of mannose only started when glucose had been almost exhausted (Fig. 1a). However, in strain BL23D both sugars were simultaneously assimilated (Fig. 1b). These data suggested that the mutation in strain BL23D affected a system that had a greater affinity for glucose than for mannose. The fact that the mutant could still grow normally on glucose and mannose, and that it could also use them simultaneously, strongly suggested the presence of an additional common 


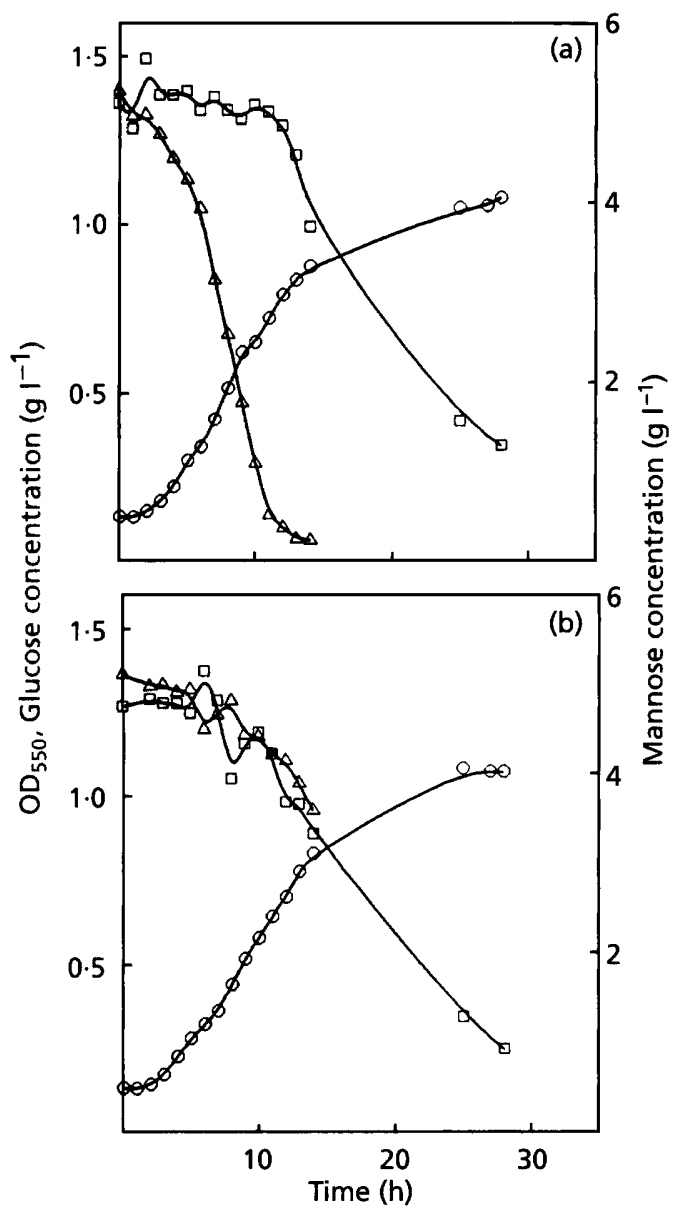

Fig. 1. Growth and sugar consumption of $L b$. case $i$ on basal medium containing glucose and mannose. $O$, Growth $\left(O D_{550}\right)$; $\triangle$, glucose concentration in the medium; $\square$, mannose concentration in the medium. (a) Wild-type; (b) mutant BL23D.

transport mechanism with identical affinity for both sugars, or independent transporters.

\section{PTS activity}

The glucose transport activity due to the PTS or a PMFdependent permease can be quantified by three different methods : (i) measurement of the glucose phosphorylation rate, in permeabilized cells, from PEP and ATP; (ii) measurement of the consumption of PEP in the presence of a given sugar by permeabilized cells; and (iii) quantification of the $\left[{ }^{14} \mathrm{C}\right]$ glucose accumulated by whole cells in the presence and in the absence of an ionophore such as CCCP.

Consumption of PEP in the presence of different sugars was used to compare the transfer of phosphate groups from PEP due to the presence of glucose, mannose and $\alpha-M G$ in cells of BL23D and the wild-type grown on glucose or mannose. Phosphorylation activity due to glucose and mannose was between 10 and 100 times greater in the wild-type than in the mutant. When cells
Table 1. Phosphorylation of glucose, mannose and $\alpha-M G$ by permeabilized cells of $L b$. casei ATCC 393 wild-type and mutant BL23D

Data shown are representative estimates, determined as the consumption of PEP in nmol $\mathrm{min}^{-1}$ (mg dry weight) $)^{-1}$.

\begin{tabular}{|c|c|c|c|c|}
\hline \multirow{2}{*}{$\begin{array}{l}\text { Cells } \\
\text { grown } \\
\text { on: }\end{array}$} & \multirow[t]{2}{*}{ Strain } & \multicolumn{3}{|c|}{ Sugar used in assay: } \\
\hline & & Glucose & Mannose & $\alpha-\mathbf{M G}$ \\
\hline \multirow[t]{2}{*}{ Glucose } & Wild-type & 48.96 & $33 \cdot 37$ & 0 \\
\hline & BL23D & $0 \cdot 19$ & 3.59 & 0 \\
\hline \multirow[t]{2}{*}{ Mannose } & Wild-type & $51 \cdot 87$ & $38 \cdot 87$ & 1.09 \\
\hline & BL23D & $2 \cdot 34$ & 6.0 & 0.92 \\
\hline
\end{tabular}

had been previously grown on either glucose or mannose, phosphoryl transfer activity was significantly higher in the presence of glucose than of mannose, while in the presence of $\alpha-M G$ it was always negligible (Table 1).

If sugar phosphorylation was taking place from PEP, as the evidence suggested, glucose and mannose phosphorylation activities were clearly diminished in the mutant. This could have been due to the main PEPdependent PTS for both sugars in $L b$. casei ATCC 393. Nevertheless, a weak phosphorylation activity was still found in mannose-preadapted cells, which could have been due to the presence of another transport mechanism for mannose, or to a differential loss of specificity of the mutated element for glucose relative to mannose. The lack of activity in the presence of $\alpha-M G$ suggested that the PEP-dependent phosphorylation was due to sugarspecific components of the IIABC ${ }^{\text {man }}$ type.

Glucose phosphorylation from PEP or ATP as phosphate group donor was also directly measured with permeabilized cells (Fig. 2a). Only a residual level of glucose was phosphorylated in the presence of PEP by the mutant. The mean apparent $K_{\mathrm{m}}$ of the reaction in the mutant $(2370 \mu \mathrm{M})$ was 100 times greater than in the wild-type $(24 \mu \mathrm{M})$. This clearly suggested that the mutant was impaired in the enzyme II $^{\text {man }}$ complex. These data were in agreement with the results obtained from PEP consumption.

The incorporation rate of $\left[{ }^{14} \mathrm{C}\right]$ glucose by wild-type $L b$. case $i$ showed a typical self-regulated PTS pattern (Mason et al., 1981). CCCP was used to dissipate the PMF necessary for solute transport by the known glucose permeases. Incorporation of $\left[{ }^{14} \mathrm{C}\right]$ glucose by the mutant was much lower than that by the wild-type (Fig. 2b). However, it ceased when CCCP was added to the reaction mixture. In the wild-type, the addition of CCCP had little effect on glucose uptake. These results indicated that, as was suggested by Chassy \& Thompson (1983a, b), the main functional transport system in $L b$. case $i$ is of the PTS $^{\text {man }}$ type, and that strain BL23D could be identified as a PTS ${ }^{\text {man}}$-deficient mutant, which could still transport glucose through a PMF-dependent permease. 

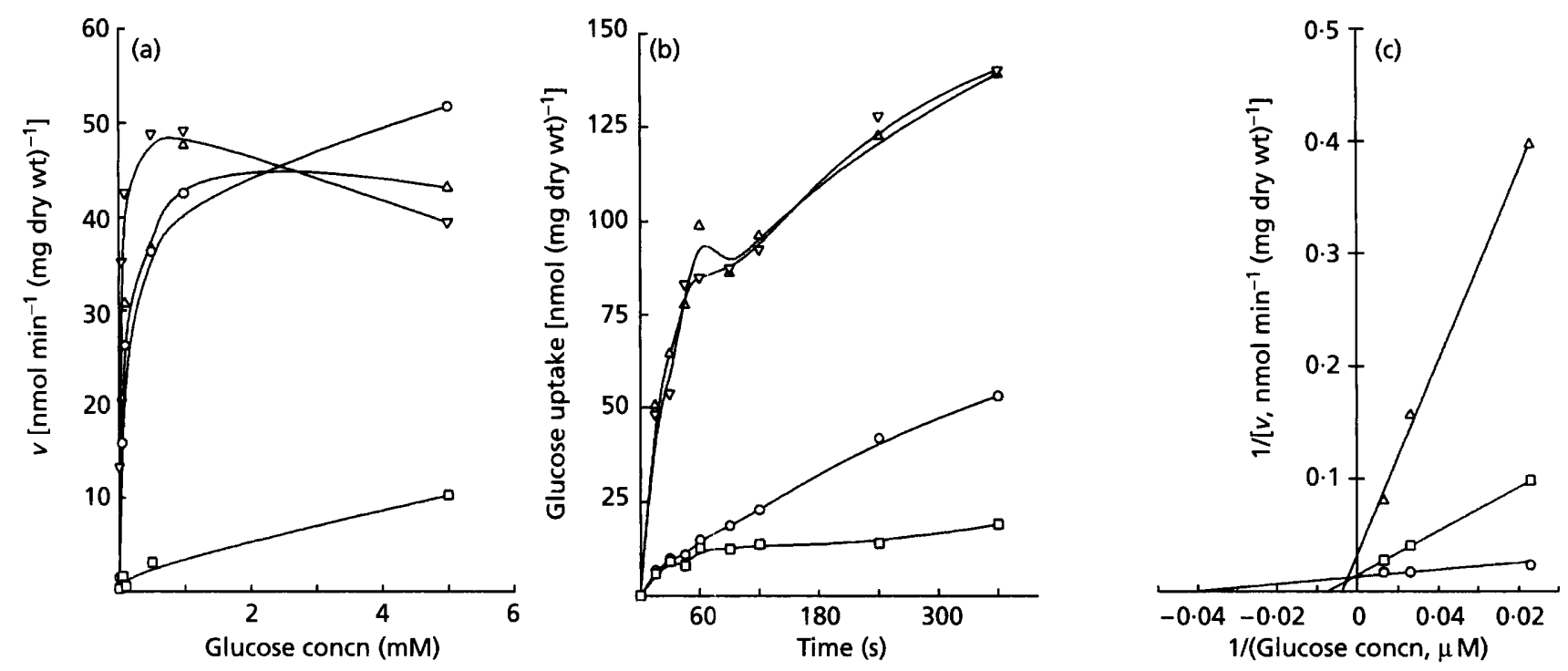

Fig. 2. Activities detected in $\angle b$. casei ATCC 393 wild-type and mutant BL23D used to characterize the glucose transport system. (a) Glucose phosphorylation activity in permeabilized cells, using as phosphate donor PEP ( $\nabla$, wild type; $\square$, BL23D) or ATP ( $\triangle$, wild-type; $O, B L 23 D)$. (b) $\left[{ }^{14} C\right]$ Glucose uptake by whole cells of the wild-type without $(\triangle)$ and with CCCP $(\nabla)$; and of BL23D without $(O)$ and with CCCP $(\square)$. (c) Inhibition kinetics, using a Lineweaver-Burk plot, of $\left[{ }^{14} \mathrm{C}\right]$ glucose uptake with increasing concentrations of mannose $(0,0 \mathrm{mM} ; \square, 1 \mathrm{mM} ; \triangle, 10 \mathrm{mM})$ by the wild-type. The estimated $K_{\mathrm{i}}$ was $115 \mu \mathrm{M}$ (1 mM mannose).

In order to confirm that Lb. casei ATCC 393 had a common uptake mechanism for glucose and mannose, $\left[{ }^{14} \mathrm{C}\right]$ glucose uptake was measured with increasing concentrations of mannose (Fig. 2c). The data indicate that there is competitive inhibition of glucose uptake by mannose. Data in the absence of mannose yielded a $K_{\mathrm{m}}$ identical to that found in the phosphorylation experiments $(24 \mu \mathrm{M})$.

\section{Growth and sugar consumption patterns}

These variables have long been used as an efficient method of studying the regulatory functions of glucose (Monod, 1942; Strobel, 1993). Pairs of sugars were added to the basal MRS medium in order to observe the preference for consumption of $L b$. casei wild-type and the P'TS ${ }^{\text {man }}$ deficient mutant, as well as their growth pattern. Glucose and mannose were initially taken as the reference sugars with which others were combined. In all cases where growth was halted after a short exponential phase, this was coincident with the exhaustion of the preferred sugar, glucose or mannose. Growth was then resumed after varying lengths of time, which depended on the nature of the second sugar in the medium and the origin of the inoculum. In most instances, substantial differences were found if the inoculum used had been grown on one or the other saccharide.

Growth on glucose and lactose. Lb. casei ATCC 393 cured of pLZ15 was chosen for these experiments because the only remaining mechanism of lactose uptake was the chromosomally encoded PTS ${ }^{\text {lac }}$. This allowed us to study, at least for this sugar, the effect of sugar transport repression caused solely by glucose. Furthermore, normal lactose uptake during growth of the PTS ${ }^{\text {man }}$-deficient mutant proved that its enzyme I and $\mathrm{HPr}$ were not affected by the mutation.

Clear differences were found between the behaviour of the mutant and the wild-type. When a glucose-grown inoculum of the wild-type was grown on basal medium with glucose and lactose, growth stopped for almost $20 \mathrm{~h}$ after glucose was consumed (Fig. 3a). This plateau was much shorter if the cells had been previously grown on lactose (Fig. 3c).

The PTS ${ }^{\text {man }}$-deficient mutant displayed no diauxic growth on glucose/lactose medium, when the inocula came from either glucose or lactose basal medium (Fig. $3 \mathrm{~b}, \mathrm{~d})$. However, differences were found with regard to sugar consumption. Cells previously grown on glucose did not start to utilize lactose until glucose levels were negligible; while in the lactose-grown inoculum the decline of both sugars in the culture medium was simultaneous.

Glucose repression of the PTS ${ }^{\text {lac }}$ and the phospho- $\beta$ galactosidase genes has been reported for different strains of Lb. casei (Chassy \& Thompson, 1983a, b); the glucose repression was relieved in 2DG-resistant mutants. However, other aspects were not considered in those experiments, such as the 'bacterial memory' shown by cultures preadapted to glucose or lactose. Hence, the repression of lactose uptake in glucose-grown cultures lasted for $20 \mathrm{~h}$, four times longer than in the lactose-grown cultures, indicating that a more stringent negative modulation of the PTS ${ }^{\text {lac }}$ elements or repression of their genes was 

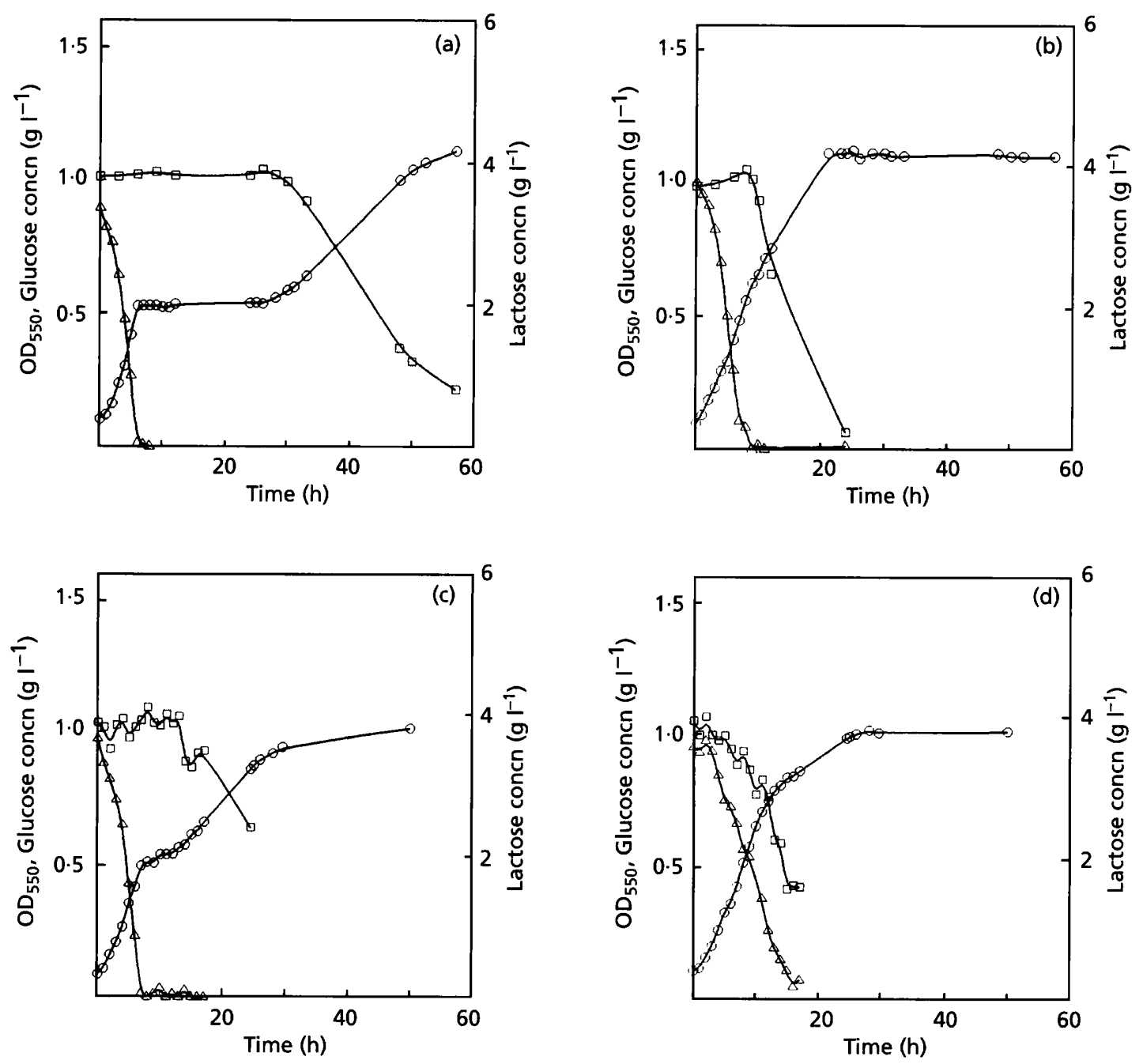

Fig. 3. Growth and sugar consumption of $L b$. casei on basal medium containing glucose and lactose. $O, G$ rowth $\left(O D_{550}\right)$; $\triangle$. glucose concentration in the medium; $\square$, lactose concentration in the medium. $(a, b)$ Wild-type (a) and PTSman. deficient mutant (b) previously grown on basal medium containing glucose; (c, d) wild-type (c) and PTSman-deficient mutant (d) previously grown on basal medium with lactose.

taking place. A retardation in lactose uptake was also observed in the glucose-grown PTS ${ }^{\text {man }}$-deficient mutant. These data clearly suggested the involvement of the mutated element of the complex IIABC in the repression of PTS ${ }^{\text {lac }}$ and/or phospho- $\beta$-galactosidase genes in $L b$. casei ATCC 393. During growth on glucose, the PMFpermease would have been fully functional, while the PTS ${ }^{\text {lac }}$ elements and the phospho- $\beta$-galactosidase would not have been induced (Fig. 3a, b).

Lactose and $\beta$-galactosides induce the PTS ${ }^{\text {lac }}$ genes (Chassy \& Thompson, 1983b); a certain degree of transport is necessary for induction. It has been suggested that PTS ${ }^{\mathrm{man}}$ in $L b$. casei and $L c$. lactis is related to the expulsion of lactose phosphate analogues (Thompson \& Saier, 1981; Chassy \& Thompson, 1983b), although other authors have attributed the inducer expulsion effect in heterofermentative lactobacilli to HPr (Reizer et al., 1988). Alternatively, exclusion of the inducer could be achieved by competition of PTS ${ }^{\text {man }}$ and $\mathrm{PTS}^{\mathrm{lac}}$ for a common phosphorylated intermediate (i.e. HPr). PTS ${ }^{\operatorname{man}}$ activity in stationary-phase $L b$. case $i$ wild-type was always high and constant [16.01-19.5 $\mathrm{nmol} \mathrm{min}^{-1}$ (mg dry weight) $\left.{ }^{-1}\right]$, regardless of whether the cells had been grown on glucose or lactose. Thus, if PTS ${ }^{\text {man }}$ elements were playing the postulated role in $L b$. casei, the constitutive PTS ${ }^{\text {man }}$ elements would promote the expulsion of lactose until glucose was totally consumed; and then the remaining PTS ${ }^{1 a c}$ molecules could slowly begin lactose transport, which would induce lactose assimilation, thus restoring growth. This hypothesis could explain the behaviour of the wild-type strain, pregrown on lactose.

The inability of the wild-type to take up lactose for $20 \mathrm{~h}$ suggested the involvement of the PTS ${ }^{\text {man }}$. The PTS ${ }^{\text {lac }}$ activity of $L b$. casei ATCC 393 grown to the stationary phase on glucose was very low $\left[1.45 \mathrm{nmol} \mathrm{min}{ }^{-1}\right.$ (mg dry weight $\left.)^{-1}\right]$. Therefore, when the cells were exposed to 

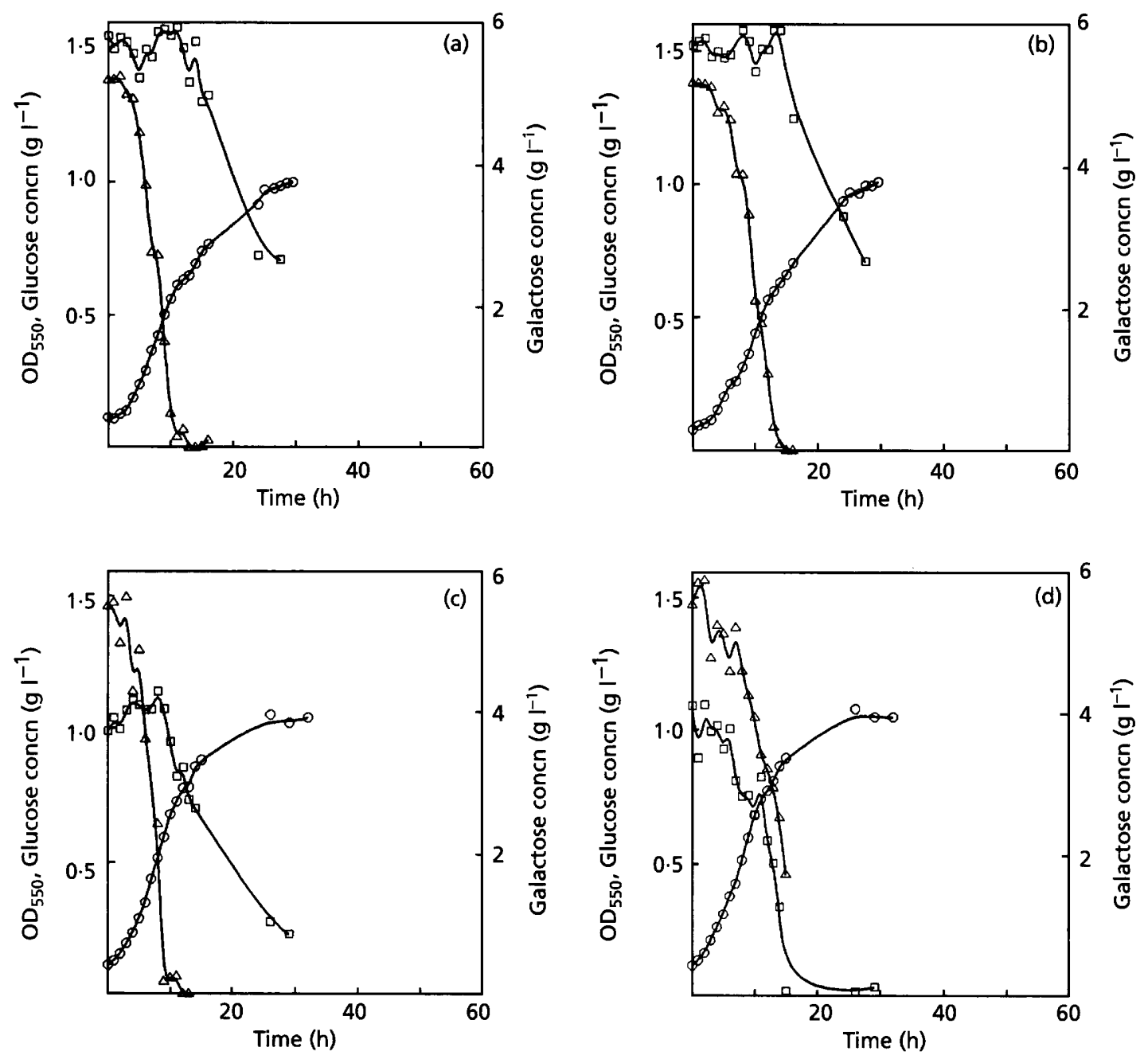

Fig. 4. Growth and sugar consumption of $L b$. casei on basal medium containing glucose and galactose. $O$, Growth $\left(O D_{550}\right) ; \triangle$ glucose concentration in the medium; $\square$, galactose concentration in the medium. (a, b) Wild-type (a) and PTS $^{\text {man }}$-deficient mutant (b) previously grown on basal medium containing glucose; (c, d) wild-type (c) and PTS ${ }^{\text {man }}$. deficient mutant (d) previously grown on basal medium with galactose.

the glucose/lactose medium, the active PTS remaining after glucose was consumed might not suffice for titrating out the repressor of a putative lactose operon. The long lag might thus correspond to a long turnover time of the PTS ${ }^{\text {man }}$-linked repressor protein. The regulation of the lactose operon in Lc. lactis was described by Van Rooijen et al. (1993); it remains to be demonstrated whether that in Lb. casei ATCC 393 is similarly regulated.

Growth on glucose and galactose. Both wild-type and mutant displayed a similar pattern of growth from both glucose-grown and galactose-grown inocula (Fig. 4) on glucose/galactose medium. The wild-type showed a faint inflexion $(1 \mathrm{~h})$ when the level of glucose was close to zero, while in the mutant such inflexion was not so clearly observed. Glucose was quickly consumed by the wildtype, and only then did galactose levels start to drop (Fig. 4a, c). This was also true for the mutant grown on glucose; but with a galactose-grown inoculum, the consumption of both sugars declined simultaneously (Fig. $4 \mathrm{~b}, \mathrm{~d})$. The behaviour of the mutant was similar to that found on basal medium with glucose and lactose, indicating that in this mutant a priority for glucose still remained after prolonged growth on glucose, galactose genes could not be induced. This indicates that some factor other than PTS ${ }^{\text {man }}$ elements, possibly a product of glucose catabolism, inhibited galactose uptake or metabolism.

Growth on mannose with lactose or galactose. A parallel has been found in this work between transport systems for glucose and those for mannose in $L b$. casei ATCC 393. To determine the role of PTS ${ }^{\text {man }}$ in the mechanism of repression, glucose-grown cells were used to inoculate mannose/lactose and mannose/galactose media in order to investigate if mannose played a similar role to glucose in the uptake of other sugars.

In the wild-type, the combination of mannose and lactose 

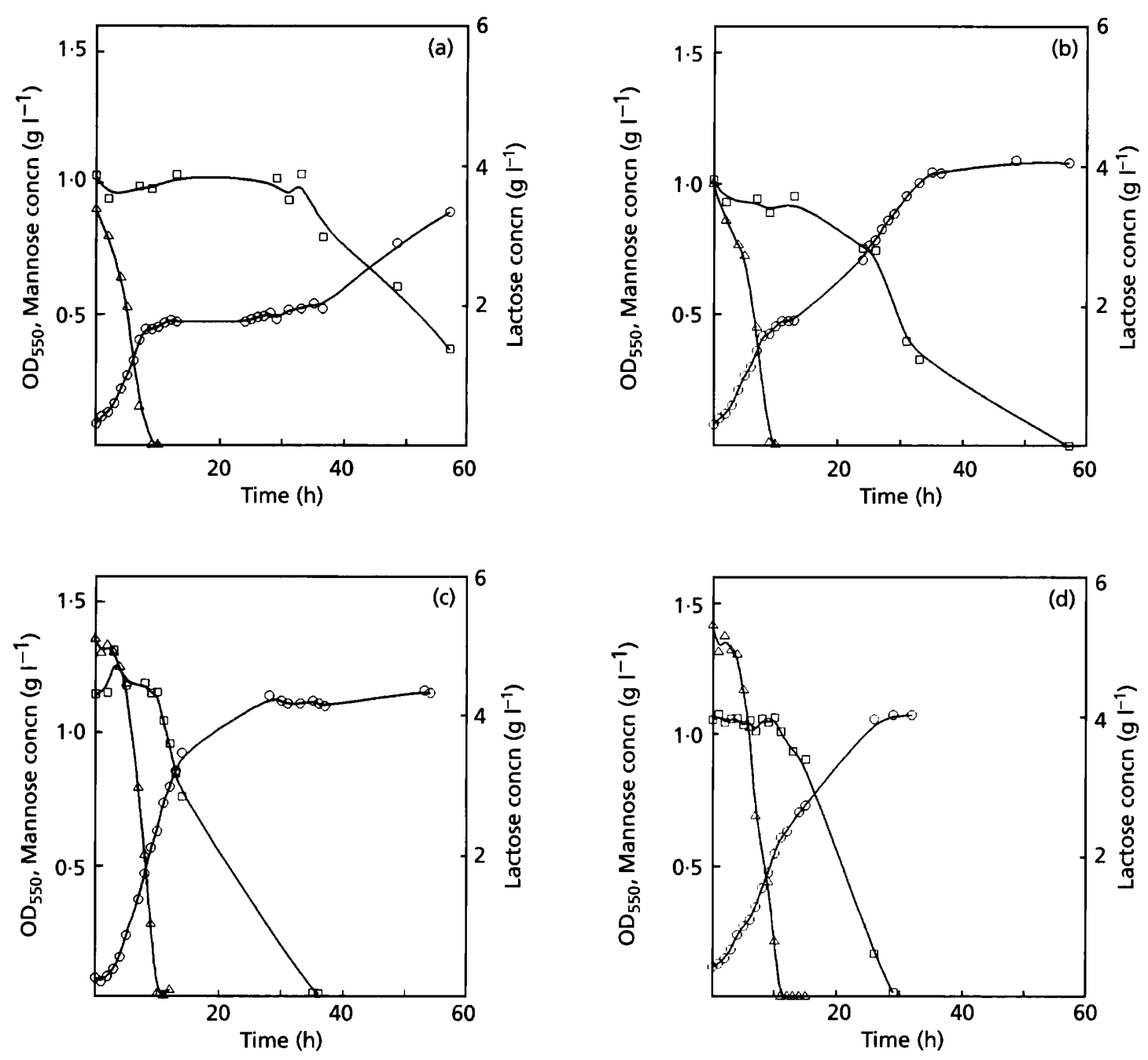

Fig. 5. Growth and sugar consumption of $L b$. casei wild-type $(a, c)$ and PTS ${ }^{\text {man }}$-deficient mutant $(b, d)$, both previously grown on glucose, on basal medium containing mannose and lactose $(a, b)$, or mannose and galactose $(c, d)$. $O$, Growth $\left(\mathrm{OD}_{550}\right) ; \triangle$, mannose concentration in the medium; $\square$, lactose or galactose concentration in the medium.

gave the same growth pattern as did glucose (Fig. 5a), with plateau of over $20 \mathrm{~h}$. In contrast to the results obtained with glucose/lactose medium, the mutant also displayed a clear diauxie (Fig. 5b), indicating that inhibition of lactose assimilation still remained. This growth stasis suggested that mannose exerted a stronger catabolic repression on the lactose genes than did glucose. Alternatively, mannose may have another repression mechanism in addition to $\mathrm{PTS}^{\text {man }}$.

On mannose/galactose medium, no clear differences were found between the two strains, apart from the difference in their growth rate (Fig. 5c, d). Apparently mannose was able to repress lactose genes, but not those related to galactose utilization.

Growth on glucose or mannose with ribose. The growth patterns of Lb. casei ATCC 393 on basal medium with ribose as the second sugar were very similar to those found with lactose. The wild-type displayed clear diauxies with either glucose or mannose and ribose, while the PTS $^{\text {man }}$-deficient mutant showed no pause in growth with glucose and ribose, although it showed a brief pause when grown on mannose and ribose (Fig. 6). These interesting results indicated that the uptake of ribose could be controlled by similar mechanisms to those regulating lactose assimilation in Lb. casei ATCC 393. This will require confirmation by biochemical and molecular studies.

\section{Conclusions}

Two aspects of glucose transport in Lb. casei ATCC 393 were addressed in this work: the transport mechanism, and its likely regulatory role in the transport of other sugars. Differences in behaviour between the wild-type and a 2DG-resistant mutant impaired in one of the elements of the complex IIABC ${ }^{\text {man }}$ were demonstrated. The mechanism itself turned out to rely mainly on a 

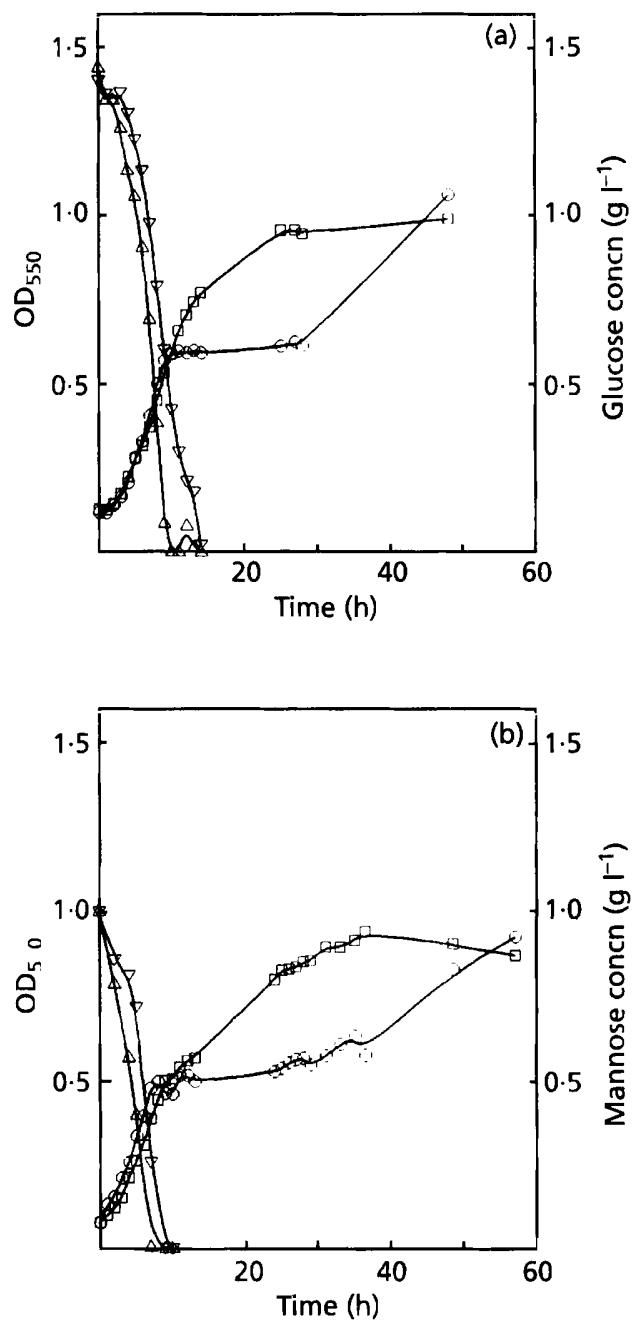

Fig. 6. Growth and sugar consumption of $L b$. casei on basal medium containing glucose and ribose (a), or mannose and ribose (b). $O$, Growth $\left(O D_{550}\right)$ of the wild-type; $\square$, growth $\left(O D_{550}\right)$ of the PTS man-deficient mutant; $\triangle$, glucose (a) or mannose (b) concentration in the medium of the wild-type; $\nabla$. glucose (a) or mannose (b) concentration in the medium of the PTS ${ }^{m a n}$-deficient mutant.

PTS $^{\text {man }}$-type of enzyme; a PMF-dependent permease could also be detected.

Elements of the IIABC complex have been related to the inhibition of uptake of other carbohydrates by three different mechanisms: inducer expulsion, modulation of transport enzymes, and genetic repression (Chassy \& Thompson, 1983a; Reizer et al., 1985). Similarly, we found that the complex IIABC ${ }^{\text {man }}$ was involved in control of the activity of the PTS ${ }^{\text {lac }}$, probably by regulating the expression of a putative lactose operon, whose repressor could have a long turnover time. Ribose assimilation could be controlled by a similar mechanism. Other important features of the system were: (i) the PTS ${ }^{\text {man }}$ linked repression of the genes controlling galactose uptake and catabolism was weaker than the repression of the lactose genes; (ii) mannose could repress the putative lactose operon as strongly as glucose, but it could not inhibit galactose uptake and assimilation, which suggested that the two groups of genes could be controlled by different mechanisms of catabolite repression; and finally (iii) preferential uptake of glucose remained in the glucose-grown PTS ${ }^{\text {man }}$-deficient mutant, suggesting that uptake of lactose and galactose was also negatively modulated by intermediates of glucose catabolism.

\section{ACKNOWLEDGEMENTS}

The authors wish to thank C.-A. Alpert for his very valuable comments on the manuscript. This work was financed by funds of the CICYT (Interministerial Commission for Science and Technology) for the research area of Food Technology. The authors wish to thank the Conselleria de Cultura, Educación y Ciencia of the Generalitat Valenciana, for the predoctoral grant held by A.V., as well as the CSIC for the grant of V.M.

\section{REFERENCES}

Abe, K. \& Uchida, K. (1989). Correlation between depression of catabolite control of xylose metabolism and a defect in the phosphoenolpyruvate:mannose phosphotransferase system in Pediococcus balophilus. J Bacteriol 171, 1793-1800.

Bergmeyer, H. U. (1984). Methods of Enzymatic Analysis, 3rd edn, vol. VI. Weinheim: Verlag Chemie.

Bitoun, R., de Reuse, H., Tonati-Schwartz, D. \& Danchin, A. (1983). The phosphoenolpyruvate dependent carbohydrate phosphotransferase system of Escherichia coli. Cloning of the ptsHI-crr region and studies with a $p t s-l a c$ operon fusion. FEMS Microbiol Lett 16, 163-167.

Chassy, B. M. \& Thompson, J. (1983a). Regulation of lactosephosphoenolpyruvate-dependent phosphotransferase system and $\beta$ D-phosphogalactosidase galactohydrolase activities in Lactobacillus casei. J Bacteriol 154, 1195-1203.

Chassy, B. M. \& Thompson, J. (1983b). Regulation and characterization of the galactose phosphoenolpy ruvate-dependent-phosphotransferase system in Lactobacillus casei.J Bacteriol 154, 1204-1214.

Erni, B. \& Zanolari, B. (1986). Glucose permease of the bacterial phosphotransferase system. J Biol Chem 261, 16398-16403.

Erni, B., Zanolari, B. \& Kocher, H. P. (1987). The mannose permease of Escherichia coli consists of three different proteins. J Biol Chem 262, 5238-5247.

Gonzy-Tréboul, G., de Waard, J. H., Zagorec, H. \& Postma, P. W. (1991). The glucose permease of the phosphotransferase system of Bacillus subtilis: evidence for II ${ }^{\mathrm{glc}}$ and $\mathrm{III}^{\mathrm{glc}}$ domains. Mol Microbiol 5, 1241-1249.

Jayne-Williams, D. J. (1976). The application of miniaturized methods for the characterization of various organisms isolated from the animal gut. J Appl Bacteriol 40, 189-200.

Lengeler, J., Aulurger, A. M., Mayer, R. \& Percher, A. (1981). The phosphoenolpyruvate-dependent carbohydrate: phosphotransferase system enzyme II as chemoreceptors in chemotaxis of Escherichia coli K-12. Mol \& Gen Genet 183, 163-170.

Mason, P. W., Carbone, D. P., Cushman, R. A. \& Waggoner, A. S. (1981). The importance of inorganic phosphate in regulation of energy metabolism of Streptococcus lactis. J Biol Chem 256, 1861-1866.

Meadow, N. D., Fox, D. K. \& Roseman, S. (1990). The bacterial phosphoenolpyruvate:glucose phosphotransferase system. Annu Rev Biochem 59, 497-542.

Monod, J. (1942). Recherches sur la croissance des cultures bactériennes. PhD thesis. Paris: Herman et Cie. 
Postma, P. W., Lengeler, J. W. \& Jacobson, G. R. (1993). Phosphoenolpyruvate: carbohydrate phosphotransferase system of bacteria. Microbiol Rev 57, 543-594.

Reizer, J., Deutscher, J., Sutrina, S., Thompson, J. \& Saier, M. H., Jr (1985). Sugar accumulation in Gram-positive bacteria : exclusion and expulsion mechanisms. Trends Biochem Sci 10, 32-35.

Reizer, J., Peterkofsky, A. \& Romano, A. H. (1988). Evidence for the presence of heat-stable protein $(\mathrm{HPr})$ and ATP-dependent $\mathrm{HPr}$ kinase in heterofermentative lactobacilli lacking phosphoenolpyruvate: glycose phosphotransferase system. Proc Natl Acad Sci US A 85, 2041-2045.

Romano, A., Trifone, J. D. \& Brustolon, M. (1979). Distribution of the phosphoenolpyruvate:glucose phosphotransferase system in fermentative bacteria. $J$ Bacteriol 139, 93-97.

Saier, M. H., Jr \& Reizer, J. (1992). Proposed uniform nomenclature for the proteins and protein domains of the bacterial phosphoenolpyruvate:sugar phosphotransferase system. J Bacteriol 174, 1433-1438.

Strobel, H. J. (1993). Evidence for catabolite inhibition in the regulation of pentose utilization and transport in the ruminal bacterium Selenomonas ruminantium. Appl Environ Microbiol 175, 40- 46.

Tanguey, M., Priest, F. G. \& Mitchell, W. J. (1993). Two glucose transport systems in Bacillus licheniformis. J Bacteriol 175, 2137-2142.

Thompson, J. \& Chassy, B. M. (1985). Intracellular phosphorylation of glucose analogs via the phosphoenolpyruvate:mannose phosphotransferase systems in Streptococcus lactis. J Bacteriol 162, 224-234.

Thompson, J. \& Saier, M. H., Jr (1981). Regulation of methyl- $\beta$ D-thiogalactopyranoside-6-phosphate accumulation in Streptococcus lactis by exclusion and expulsion mechanism. I Bacteriol 146, 885-894.

Van Rooijen, R. J., Dechering, K. J., Niek, C., Wilmink, J. \& de Vos, W. M. (1993). Lysines 72, 80 and 213 and aspartic acid 210 of the Lactococcus lactis Lac $\mathrm{R}$ repressor are involved in the response to the inducer tagatose-6-phosphate leading to lac operon expression. Protein Eng 6, 201-206.

Received 28 June 1993; revised 15 November 1993; accepted 7 December 1993. 